\title{
The Natural Compound Myricetin Effectively Represses the Malignant Progression of Prostate Cancer by Inhibiting PIM1 and Disrupting the PIM1/ CXCR4 Interaction
}

\author{
Chen Ye ${ }^{a}$ Chao Zhang ${ }^{a}$ Hai Huang ${ }^{b}$ Bo Yang ${ }^{a}$ Guangan Xiao ${ }^{a}$ Depei Kong ${ }^{a}$ \\ Qinqin Tian $^{\mathrm{a}}$ Qixiang Song ${ }^{\mathrm{a}}$ Yunjie Song ${ }^{\mathrm{c}}$ Haisong Tan ${ }^{\mathrm{b}}$ Yang Wang $^{\mathrm{d}}$ \\ Tie Zhou ${ }^{a} \quad$ Xiaoyuan $Z^{a}$ Yinghao Sun ${ }^{a}$ \\ aDepartment of Urology, Changhai Hospital, Second Military Medical University, Shanghai, \\ bDepartment of Urology, Changzheng Hospital, Second Military Medical University, Shanghai, cSchool \\ of Pharmacy, Fudan University, Shanghai, dDepartment of Pathology, Shanghai Changhai Hospital, \\ Second Military Medical University, Shanghai, China
}

\section{Key Words}

Prostate cancer • Myricetin • PIM1 • CXCL12-CXCR4 axis • Small molecular inhibitor

\begin{abstract}
Background/Aims: Natural compounds are a promising resource for anti-tumor drugs. Myricetin, an abundant flavonoid found in the bark and leaves of bayberry, shows multiple promising anti-tumor functions in various cancers. Methods: The cytotoxic, pro-apoptotic, and anti-metastatic effects of myricetin on prostate cancer cells were investigated in both in vitro and in vivo studies. Short-hairpin RNA knockdown of the proviral integration site for Moloney murine leukemia virus-1 (PIM1), pull-down and co-immunoprecipitation assays, and an intracellular $\mathrm{Ca}^{2+}$ flux assay were used to investigate the potential underlying mechanism of myricetin. ONCOMINE database data mining and immunohistochemical analysis of prostate cancer tissues were used to evaluate the expression of PIM1 and CXCR4, as well as the correlation between PIM1 and CXCR4 expression and the clinicopathologic characteristics and prognoses of prostate cancer patients. Results: Myricetin exerted selective cytotoxic, pro-apoptotic, and anti-metastatic effects on prostate cancer cells by inhibiting PIM1 and disrupting the PIM1/CXCR4 interaction. Moreover, PIM1 and CXCR4 were coexpressed and associated with aggressive clinicopathologic traits and poor prognosis in prostate cancer patients. Conclusion: These results offer preclinical evidence for myricetin as a potential chemopreventive and therapeutic agent for precision medicine tailored to prostate cancer patients characterized by concomitant elevated expression of PIM1 and CXCR4.
\end{abstract}

Chen Ye, Chao Zhang and Hai Huang contributed equally to this work.

Xiaoyuan Zi

and Yinghao Sun

\section{KARGER}




\section{Cellular Physiology Cell Physiol Biochem 2018:48:1230-1244 \begin{tabular}{ll|l} 
DOI: 10.1159/000492009 & $\begin{array}{l}\text { C } 2018 \text { The Author(s). Published by S. Karger AG, Base } \\
\text { www.karger.com/cpb }\end{array}$ \\
\cline { 2 - 3 } & Published online: July 25, 2018 &
\end{tabular} \\ Ye et al.: Myricetin Represses Prostate Cancer Progression by Inhibiting PIM1 and PIM1/ CXCR4 Interaction}

\section{Introduction}

Prostate cancer ( $\mathrm{PCa}$ ) is the second most frequently diagnosed cancer and the fifth leading cause of cancer-related death among males worldwide [1]. Although androgen deprivation therapy can control the progression of advanced PCa during the initial phase, nearly all patients eventually develop lethal metastatic castration-resistant prostate cancer. Therefore, the development of novel agents with an explicit mechanism for advanced PCa is vital and urgently needed.

Laboratory and clinical studies have reported that flavonoid compounds, found in various fruits and vegetables, are effective in cancer chemoprevention and chemotherapy [2]. Moreover, recent studies have indicated that flavonoids play important roles in antitumor activities [3-6]. Myricetin is an abundant flavonoid in the bark and leaves of bayberry, and epidemiological research has shown that myricetin consumption is associated with a lower risk of some cancers, such as breast, pancreatic, and prostate cancer [7-9]. Moreover, studies have further indicated that myricetin exerts multiple promising anti-tumor functions in various cancers, including anti-proliferative, pro-apoptotic, and anti-metastatic activities [10-15]. However, its definitive anti-tumor effects and underlying mechanism in PCa are unclear.

The proviral integration site for Moloney murine leukemia virus-1 (PIM1), a Ser/Thr protein kinase in the PIM family, is a proto-oncogene protein that is overexpressed in PCa $[16,17]$. PIM1 plays important roles in tumorigenesis, castration resistance, and metastasis in PCa [18-20]. Moreover, PIM1 facilitates the phosphorylation and surface expression of CXCR4, further supporting the CXCL12-CXCR4 axis, which significantly promotes cancer proliferation and metastasis $[18,21]$. Cell-free crystallographic and comparative molecular field analyses showed that myricetin binds to the ATP-binding pocket of PIM1 and further inhibits its kinase activity ( $\mathrm{IC}_{50}: 780 \mathrm{nM}$ ) [22]. However, it is unknown whether myricetin represses tumor progression by inhibiting PIM1 and further suppressing CXCR4 in PCa.

In our study, via in vitro and in vivo experiments, we found that myricetin exerted selective cytotoxic, pro-apoptotic, and anti-metastatic effects by inhibiting PIM1 and further disrupting the PIM1/CXCR4 interaction in PCa cells. Moreover, we found that coexpression of PIM1 and CXCR4 was significantly correlated with aggressive clinicopathologic traits and could predict poor prognosis for PCa patients. Therefore, our findings provide novel insights into the role of myricetin as a potential chemopreventive and therapeutic agent that represses the malignant progression of PCa, particularly in patients with high PIM1 and CXCR4 expression levels.

\section{Materials and Methods}

\section{Clinical tissue samples and cell lines}

Human PCa tissues were obtained from the biobank of Shanghai Changhai Hospital with informed consent. The project was approved and supervised by the Clinical Research Ethics Committee of Changhai Hospital. Prostate cancer cell lines (PC3, DU145) and the normal prostate epithelial cell line RWPE-1 were obtained from the American Type Culture Collection (Manassas, VA). The C4-2 [23] cell line was obtained from Prof. Leland W.K. Chung (Department of Medicine, Cedars-Sinai Medical Center). PC3 cells were infected with a recombinant lentivirus containing luciferase and mCherry (OBIO TEC, Shanghai, China) and selected with puromycin (Gibco, Grand Island, NY) to obtain luciferase- and mCherry-labeled PC3 cells (PC3-luc-mCfp). Short-hairpin RNA targeting PIM1 (shPIM1) and a negative control (shNC) were purchased from GeneChem (Shanghai, China). The access ID was GIEP1121099348. The shRNA plasmids were transfected into PC3 cells following the manufacturer's instructions. All cancer cells were grown in RPMI 1640 supplemented with $10 \%$ fetal bovine serum (Gibco). RWPE-1 cells were grown in Keratinocyte-SFM supplemented with epidermal growth factor and bovine pituitary extract (Gibco). All cells were maintained at $37^{\circ} \mathrm{C}$ in a humidified incubator containing $5 \% \mathrm{CO}_{2}$. 


\section{Cellular Physiology Cell Physiol Biochem 2018;48:1230-1244

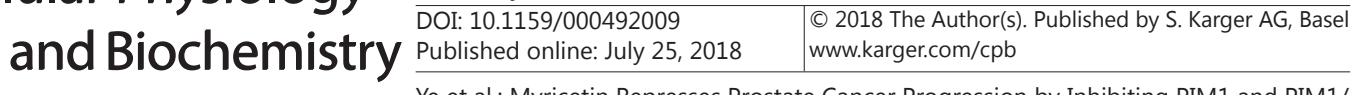 \\ Ye et al.: Myricetin Represses Prostate Cancer Progression by Inhibiting PIM1 and PIM1/ CXCR4 Interaction}

\section{Reagents and antibodies}

The following primary antibodies were used: alpha-tubulin (HRP-66031; western blot [WB]: 1:5000; Proteintech, Wuhan, China), vimentin (10366-1; WB: 1:1000, immunohistochemistry [IHC]: 1:500, immunofluorescence [IF]: 1:50; Proteintech), E-cadherin (20874-1; WB: 1:1000, IHC: 1:100, IF: 1:50; Proteintech), N-cadherin (22018-1; WB: 1000, IHC: 1:50, IF: 1:50; Proteintech), Ki-67 (27309-1; IHC: 1:2000; Proteintech), AKT (10176-2; WB: 1:500; Proteintech), ERK1/2 (16443-1; WB: 1:1000; Proteintech), pAKT (4060; WB: 1:1000; Cell Signaling Technology, Danvers, MA), pERK1/2 (4695, WB: 1:1000; Cell Signaling Technology), cleaved caspase-3 (29034; WB: 1:1000, IHC: 1:50; Signalway Antibody, College Park, MD), cleaved caspase-9 (40504; WB: 1:1000; Signalway Antibody), CXCR4 (ab124824; IHC: 1:500; Abcam, Cambridge, MA), CXCR4 (11073-2; WB: 1:1000, IP: 4 g; Proteintech), pCXCR4-S339 (74012; WB: 1:200; Abcam), PIM1 (54523; WB: 1:1000, IP: 1:200; Cell Signaling Technology), PIM2 (4730; WB: 1:1000, IP: 1:100; Cell Signaling Technology), and PIM1 (ab224772; IHC: 1:100; Abcam). Anti-rabbit and anti-mouse IgG antibodies conjugated to HRP, FITC, or PE were purchased from Proteintech.

\section{Cell Counting Kit-8 and colony formation assays}

Cells were plated in 96-well plates (4000 cells/well) and incubated overnight. Then, the myricetin stock solution was further diluted with complete culture medium to the indicated final concentrations and added to the wells for treatment. After a 48-h incubation, the cell viability was measured by a Cell Counting Kit-8 (CCK-8) (Dojindo, Kumamoto, Japan) with an ELx800 ${ }^{\mathrm{TM}}$ plate reader (BioTek, Winoosky, VT). The halfmaximal inhibitory concentration $\left(\mathrm{IC}_{50}\right)$ of myricetin was estimated using SPSS 19.0 software (IBM, Armonk, NY). For the colony formation assay, cells were plated in 6-well plates (2000 cells/well) and incubated for $24 \mathrm{~h}$ prior to treatment. Medium containing myricetin was replaced every 3 days. After the cells were treated for 9 days, they were fixed with $4 \%$ paraformaldehyde and stained with crystal violet stain (Sangon, Shanghai, China). After being washed, the plates were photographed. The numbers of colonies were counted using ImageJ software (National Institutes of Health, Bethesda, MD).

\section{Cell apoptosis and membrane protein expression analyses}

Cell apoptosis and CXRC4 surface expression were evaluated by flow cytometry analysis with MACSQuant Analyzers (Miltenyi, Bergisch Gladbach, Germany). The apoptosis levels were determined using an Annexin V-FITC/PI Apoptosis Detection kit (BD Biosciences, Franklin Lakes, NJ). In addition, CXCR4 was detected by staining with PE-conjugated anti-human CD184 antibody (BD Biosciences). Nonspecific binding was assessed with PE-conjugated mouse IgG2a (BD Biosciences) as an isotype control.

\section{WB analysis}

Total protein was extracted with RIPA buffer containing a protease and phosphatase inhibitor cocktail (Thermo Fisher Scientific, Waltham, MA). Total protein was separated using sodium dodecyl sulfate polyacrylamide gel electrophoresis (SDS-PAGE) and transferred to polyvinylidene fluoride membranes (Merck Millipore, Burlington, MA), which were blocked in 5\% bovine serum albumin and immunoblotted with the appropriate primary and second antibodies according to standard procedures. Finally, the signals of specific proteins were determined using an enhanced chemiluminescence detection substrate kit (BioTools, Jupiter, FL) with an Amersham Imager 600 (GE Healthcare, Marlborough, MA). Quantification analysis was performed by ImageJ software. Protein levels were normalized to alpha-tubulin.

\section{Wound-healing and Transwell assays}

For the wound-healing assay, cells were plated in 6 -well plates $\left(2 \times 10^{5}\right.$ cells/well $)$ with complete medium and incubated for $24 \mathrm{~h}$. Wounds were created by scratching the cell monolayer with a $10-\mu \mathrm{L}$ pipette tip. The cells were then incubated with serum-free medium containing myricetin. Wound closure was observed and photographed at the indicated times under a microscope at $40 \times$ magnification and quantified by measuring the wound width using Image software. The wound width at $0 \mathrm{~h}$ was designated $100 \%$. For the Transwell assay (with or without a Matrigel-coated membrane), cells that had been serum starved for $24 \mathrm{~h}$ were seeded in the upper chamber of Transwell inserts (Corning Inc., Corning, NY) (5 × $10^{4}$ cells/ insert) and cultured in serum-free medium containing myricetin. The lower chamber contained complete medium. After $48 \mathrm{~h}$, the cells on the upper surface of the membranes were removed with cotton swabs. The membranes were fixed with $4 \%$ paraformaldehyde and stained with crystal violet. Five random fields of 


\section{Cellular Physiology Cell Physiol Biochem 2018;48:1230-1244

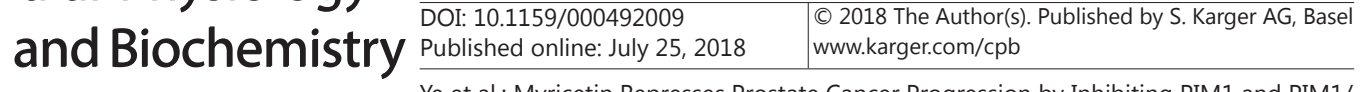 \\ Ye et al.: Myricetin Represses Prostate Cancer Progression by Inhibiting PIM1 and PIM1/ CXCR4 Interaction}

each membrane were photographed under a microscope at 100× magnification. The numbers of trespassed cells were calculated with ImageJ software. Similarly, migration induced by CXCL12 (Sino Biological, Beijing, China) was tested using the Transwell assay (without the Matrigel-coated membrane).

\section{RNA extraction and quantitative real-time PCR}

Total RNA was extracted by the RNAiso Plus reagent (Takara Bio, Kusatsu, Japan), and cDNA was synthesized using the PrimeScript RT reagent kit (Takara). Quantitative real-time PCR (qRT-PCR) analyses were performed using a SYBR qPCR Mix (TOYOBO, Japan) on a StepOne-plus Real-Time PCR system (ABI, USA). The following primers were used for qRT-PCR: vimentin (forward, 5'-TAT GAA GGA GGA AAT GGCT3'; reverse, 5'-AGT TTG GAA GAG GCA GAGA-3'); E-cadherin (forward, 5'-GCC CCA TCA GGC CTC CGT TT-3'; reverse, 5'-ACC TTG CCT TCT TTG TCT TTG TTG GA-3'); N-cadherin (forward, 5'-TGG ACC ATC ACT CGG CTTA-3'; reverse, 5'-ACA CTG GCA AAC CTT CACG-3'); and $\beta$-actin (forward, 5'-GGG AAA TCG TGC GTG ACA TTA AG-3'; reverse, 5'-TGT GTT GGC GTA CAG GTC TTTG-3').

\section{IHC analysis}

Formalin-fixed and paraffin-embedded tissues from xenografted mice and clinical prostate cancer tissues were cut into 5- $\mu$ m sections with an autostainer (Leica, Wetzlar, Germany). After antigen retrieval, an IHC staining kit (UltraSensitive S-P \& DAB, MaXim, Fuzhou, China) and specific antibodies or hematoxylin and eosin were used according to the manufacturers' protocols. After the stained sections were mounted with neutral balsam mounting medium (Sangon), all of the images were observed and imaged at either 200x or $400 \times$ magnification. The staining levels of target proteins in samples were independently examined by two pathologists. The H-score method was used to semiquantitatively analyze the immunoreactivity [24]. The intensity grades of target proteins were defined as 0 (negative), 1 (weak), 2 (moderate), and 3 (strong), and the estimated percentage (0-100\%) of tumor cells at each intensity grade was recorded. The H-score is the sum of the products of each intensity grade $(0-3)$ and the corresponding percentage score (0-100) and ranges from 0 to 300. For clinical PCa specimens, cases were classified into low- or high-expression groups using the median H-score (180) as the threshold, based on the H-score of PIM1 and CXCR4.

\section{IF analysis}

Cells were plated on round coverslips (NEST, Wuxi, China) in 6-well plates $\left(1 \times 10^{5}\right.$ cells/well). After a 24-h incubation, the cells were treated with myricetin for a set duration. Then, the cells were fixed with $4 \%$ paraformaldehyde and permeabilized with $0.4 \%$ Triton X-100. After the samples were blocked with goat serum, they were incubated with specific primary antibodies overnight at $4{ }^{\circ} \mathrm{C}$ and stained with the corresponding FITC- or PE-labeled secondary antibodies for $3 \mathrm{~h}$ at room temperature. The sections were then mounted with anti-fade mounting medium, and all samples were observed and imaged under a Leica DMI4000B fluorescence microscope (magnification, $400 \times$ or $1000 \times$ ) with the LAS X application (Leica).

\section{In vivo assays of tumor growth and metastasis}

All experimental animal procedures were approved by the Animal Care and Use Committee of the Second Military Medical University, Shanghai, China. Athymic nude mice (male, 4-5 weeks old) were purchased from the Shanghai Laboratory Animal Center (Shanghai, China) and housed under specific pathogen-free conditions. Myricetin was dissolved in 4\% DMSO and 30\% PEG300 (Sigma-Aldrich, St. Louis, MO) in phosphate-buffered saline (PBS) according to the manufacturer's instructions. To explore the effects of myricetin on tumor growth in vivo, $200 \mu \mathrm{L}$ of a PC3 cell suspension in PBS and Matrigel solution (1:1 $\mathrm{v} / \mathrm{v}$ ) was subcutaneously injected into the right flank of each mouse $\left(5 \times 10^{6} /\right.$ mouse). Five days after the inoculation, tumor-bearing mice were randomly divided into myricetin and vehicle control groups $(\mathrm{n}=$ 6/group). Either myricetin $(25 \mathrm{mg} / \mathrm{kg}$ ) or vehicle was administered once every 2 days by intraperitoneal injection, and the tumor volume was measured every 5 days and calculated as (length $\left.\times w^{2} i_{t h}{ }^{2}\right) / 2$. On day 45 after inoculation, the mice were euthanized to allow for the excision of the xenograft tumors for imaging, followed by freezing and fixation for further analyses.

To explore the effects of myricetin on tumor metastasis in vivo, we established tail vein injection and intratibial injection mouse models. PC3-luc-mCfp cells were injected into mouse tail veins $\left(2 \times 10^{6}\right.$ cells in $100 \mu \mathrm{L}$, suspended in PBS) and tibial intramedullary cavities $\left(1 \times 10^{5}\right.$ in $20 \mu \mathrm{L}$, suspended in PBS and Matrigel $(1: 1 \mathrm{v} / \mathrm{v}))$. Three days after the inoculation, the mice were randomly divided into myricetin and 


\section{Cellular Physiology Cell Physiol Biochem 2018;48:1230-1244 \\ \begin{tabular}{l|l} 
DOI: 10.1159/000492009 & $\begin{array}{l}\text { () 2018 The Author(s). Published by S. Karger AG, Basel } \\
\text { www.karger.com/cpb }\end{array}$ \\
\hline
\end{tabular} \\ Ye et al.: Myricetin Represses Prostate Cancer Progression by Inhibiting PIM1 and PIM1/ CXCR4 Interaction}

vehicle control groups (tail vein: $n=6 /$ group; tibia: $n=3$ /group), and the treatments were administered as described above. After an intraperitoneal injection of $3 \mathrm{mg}$ of luciferin (Gold Biotechnology, Inc., Olivette, MO) in $100 \mu \mathrm{L}$ of DPBS, the metastases were monitored on an IVIS Lumina III system (PerkinElmer, Waltham, MA). The destruction of the tibia was further monitored using a Quantum GX microCT system (PerkinElmer).

At the end of the experiments, we collected whole-blood samples from the tail vein injection model mice. Flow cytometric analysis was performed as described above to count mCherry-positive circulating tumor cells (CTCs). In addition, the human LINE1 DNA level was determined by performing qRT-PCR of genomic DNA from whole blood and the results were normalized to mouse LINE1 DNA. The following primers were used: human LINE1 (forward, 5'-AAA GCC GCT CAA CTA CAT GG-3'; reverse, 5'-TGC TTT GAA TGC GTC CCA GAG-3') and mouse LINE1 (forward, 5'-CAT CCA AAC GCT GAC ACC A-3'; reverse, 5'-CCC TGT GAT CCG TCC ATTA-3'). Whole blood from mice without tumors was used as a negative control.

Pull-down and co-immunoprecipitation assays

In pull-down assays, myricetin was conjugated with epoxy-activated sepharose 6B (GE Healthcare) following the manufacturer's protocol. PC3 cells were lysed in RIPA buffer containing proteinase inhibitors (Thermo Fisher Scientific). Then, the cell lysate was mixed with myricetin-conjugated or control sepharose $6 \mathrm{~B}$ beads at $4{ }^{\circ} \mathrm{C}$ for $24 \mathrm{~h}$. After three washes with TBST buffer, the bound proteins were resolved by SDSPAGE followed by WB.

In co-immunoprecipitation assays, after being treated with myricetin for $12 \mathrm{~h}$, PC3 cells were further lysed in RIPA buffer containing proteinase inhibitors (Thermo Fisher Scientific). After protein concentration determination by bicinchoninic acid assay (Thermo Fisher Scientific), the cell lysates were separately mixed with anti-CXCR4, anti-PIM1, or normal rabbit IgG (Cell Signaling Technology) at $4{ }^{\circ} \mathrm{C}$ for $2 \mathrm{~h}$, followed by the addition of Protein A/G Plus-Agarose (Santa Cruz Biotechnology, Santa Cruz, CA) at $4{ }^{\circ} \mathrm{C}$ overnight with gentle rocking. After three washes with RIPA buffer, the bound proteins were further analyzed by WB.

\section{Intracellular $\mathrm{Ca}^{2+}$ flux assay}

Cells were plated in 6-well plates $\left(1 \times 10^{5}\right.$ cells/well) and incubated for $24 \mathrm{~h}$. After being treated with myricetin for $6 \mathrm{~h}$, the cells were further incubated with the fluorescent calcium indicator Fluo- 4 (Dojindo) following the manufacturer's protocol. Then, the intracellular $\mathrm{Ca}^{2+}$ concentrations of the treated cells were monitored in real time under a Leica TCS SP5 confocal microscope with the LAS X application (Leica) before and after stimulation of the cells with CXCL12 (400 ng/mL).

\section{Statistical analysis}

Statistical analyses were performed using GraphPad Prism 6 (GraphPad Software, La Jolla, CA) and SPSS 19 (IBM). Numerical data are expressed as the means \pm standard deviation of three independent experiments performed in triplicate. Differences between variables were assessed by a two-tailed Student's t-test, Mann-Whitney test, chi-square test, or Fisher's exact test. Spearman's correlation analysis was performed to assess the relationship between PIM1 and CXCR4 in human PCa specimens. Survival was assessed by Kaplan-Meier analysis and log-rank test analysis. A p value $<0.05$ was considered statistically significant $\left({ }^{*} \mathrm{p}<0.05 ;{ }^{* *} \mathrm{p}<0.01 ;{ }^{* * *} \mathrm{p}<0.001\right)$.

\section{Results}

Myricetin exerts cytotoxic and apoptosis-promoting effects in PCa cells

We examined the cytotoxic and apoptosis-promoting effects of myricetin in PC3, DU145, C4-2, and RWPE-1 cells. First, myricetin cytotoxicity was examined using CCK-8 and colony formation assays. Our data showed that myricetin was significantly cytotoxic to PCa cells (Fig. 1A and B). However, the normal prostate epithelial cell line RWPE-1 was less sensitive to myricetin than tumor cells. The $\mathrm{IC}_{50}$ values of myricetin in PC3, DU145, C4-2, and RWPE-1 cells were 47.6 $\mu \mathrm{M}, 55.3 \mu \mathrm{M}, 79.9 \mu \mathrm{M}$, and 362.1 $\mu \mathrm{M}$, respectively. Flow cytometry analysis further showed that myricetin significantly induced apoptosis in PCa cells (Fig. 1C). Meanwhile, lower apoptosis rates were observed in RWPE-1 cells, in accordance with the cytotoxicity assays. Consistently, WB analysis showed that the expression levels of the 


\section{Cellular Physiology Cell Physiol Biochem 2018;48:1230-1244 \begin{tabular}{l|l} 
DOI: 10.1159/000492009 & $\begin{array}{l}\text { @ 2018 The Author(s). Published by S. Karger AG, Basel } \\
\text { www.karger.com/cpb }\end{array}$ \\
\hline
\end{tabular} \\ Ye et al.: Myricetin Represses Prostate Cancer Progression by Inhibiting PIM1 and PIM1/ CXCR4 Interaction}

apoptosis-related proteins cleaved caspase- 3 and cleaved caspase- 9 were both upregulated in PC3 and DU145 cells after myricetin treatment (Fig. 1D). Moreover, myricetin inhibited the phosphorylation of ERK1/2 and AKT in PC3 and DU145 cells (Fig. 1D). These results demonstrate that myricetin has selective cytotoxic and apoptosis-promoting effects in PCa cells.

Myricetin inhibits migration, invasion, and the epithelial-mesenchymal transition in $\mathrm{PCa}$ cells

Myricetin suppresses metastasis in many cancers $[12,13]$. To determine the effects of myricetin on migration and invasion in PCa cells, we performed wound-healing and Transwell (with or without a Matrigel-coated membrane) assays in PC3 and DU145 cells (Fig. 2A and B). To avoid an excessive impact on cell viability, we reduced the concentration of myricetin to 25 or $50 \mu \mathrm{M}$ for the experiments. As expected, myricetin significantly inhibited the migration and invasion of PCa cells.

The epithelial-mesenchymal transition (EMT) plays significant roles in cancer progression and metastasis [25]. To determine the effect of myricetin on the EMT in PCa cells, WB and IF analyses were used to assess the changes in the epithelial marker E-cadherin and the mesenchymal markers N-cadherin and vimentin (Fig. 2C and D). We observed that E-cadherin was upregulated but $\mathrm{N}$-cadherin and vimentin were downregulated with myricetin treatment. These results revealed a dose-dependent effect of myricetin treatment and demonstrate that myricetin inhibits migration, invasion, and the EMT in PCa cells.

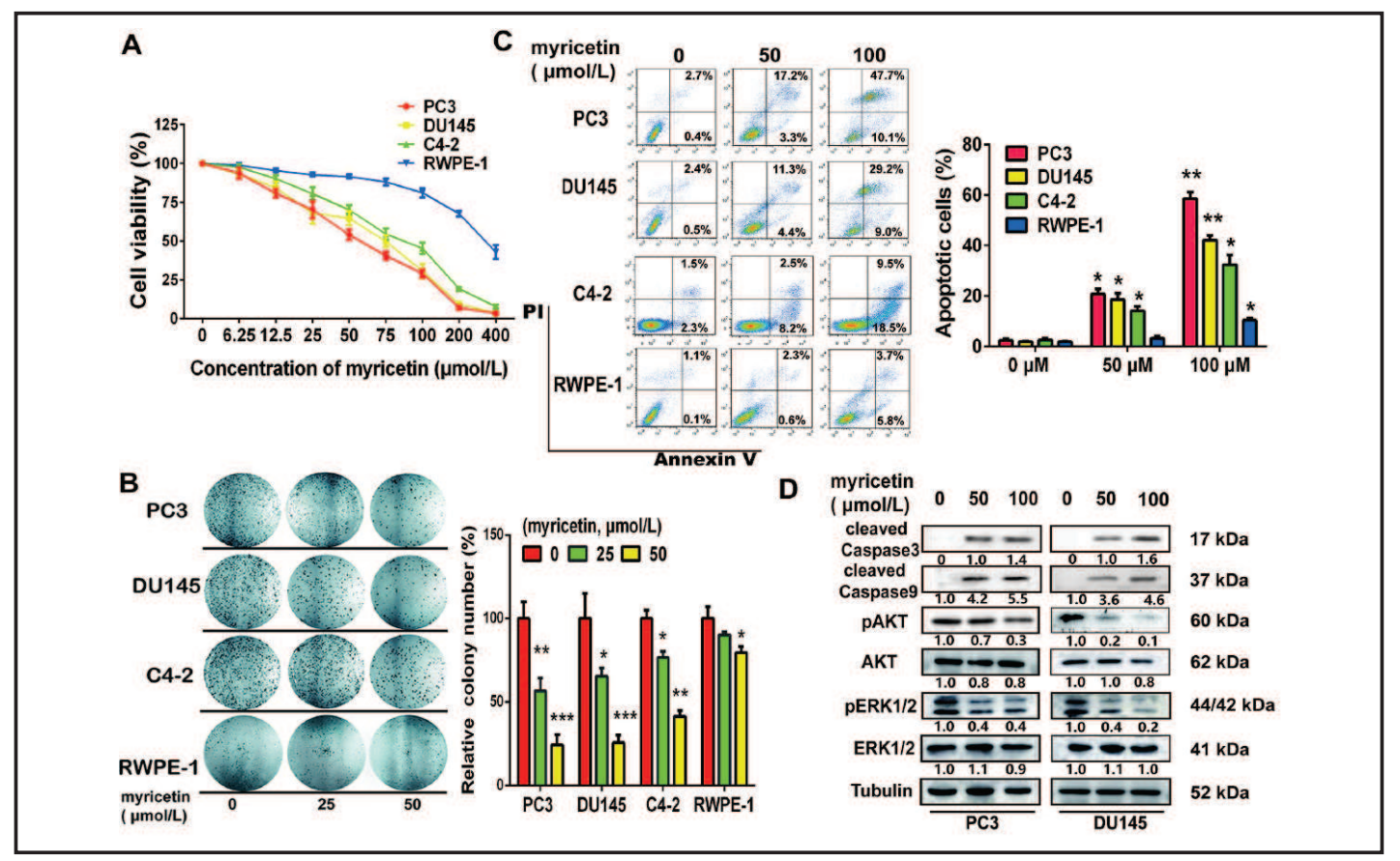

Fig. 1. Myricetin shows cytotoxic and apoptosis-promoting effects in PCa cells. (A) Cell viability was examined using the CCK-8 assay in PC3, DU145, C4-2, and RWPE-1 cells treated with the indicated concentrations of myricetin for $48 \mathrm{~h}$. Data from each cell line are shown as the mean \pm standard deviation based on four duplicates per concentration. (B) Colony formation assay of PC3, DU145, C4-2, and RWPE-1 cells after treatment with 0,25 , or $50 \mu \mathrm{mol} / \mathrm{L}$ myricetin for 9 days. Images are representative of at least three independent experiments. Quantification analysis is presented in the right panel. (C) Apoptosis was examined by flow cytometry analysis using PI/Annexin V-FITC double-staining in PC3, DU145, C4-2, and RWPE-1 cells. Cells were treated with 0,50 , or $100 \mu \mathrm{mol} / \mathrm{L}$ myricetin for $48 \mathrm{~h}$. Images are representative of at least three independent experiments. Quantification analysis is presented in the right panel. (D) Analysis of cleaved caspase-3, cleaved caspase-9, pERK1/2, and pAKT levels in PC3 and DU145 cells by WB. Cells were treated with 0,50 , or $100 \mu \mathrm{mol} / \mathrm{L}$ myricetin for $48 \mathrm{~h}$. 


\section{Cellular Physiology Cell Physiol Biochem 2018;48:1230-1244 \begin{tabular}{ll|l} 
DOI: 10.1159/000492009 & O 2018 The Author(s). Published by S. Karger AG, Basel \\
\hline wund Biochemistry
\end{tabular} and Biochemistry $\frac{\text { Publs.: Myricetin Represses Prostate Cancer Progression by Inhibiting PIM1 and PIM1/ }}{Y_{e} \text { et al }}$ CXCR4 Interaction}

\section{Myricetin inhibits PCa growth and the EMT in mouse models}

Considering the anti-tumor effects of myricetin on PCa cells in vitro, we further investigated the inhibitory effects of myricetin on growth and the EMT in vivo by establishing a PC3 subcutaneous xenograft model in nude mice. The photographs and growth curves of xenograft tumors showed that myricetin significantly repressed the growth of xenograft tumors (Fig. 3A and B). Then, IHC analysis of the xenograft tumors showed that the myricetin group had a higher cleaved caspase-3 level and a lower Ki-67 level than the vehicle group (Fig. 3C). Moreover, IHC analysis of xenograft tumors showed that the myricetin group had both higher E-cadherin and lower N-cadherin and vimentin levels than the vehicle group (Fig. 3D). No obvious loss of body weight was observed in the myricetin group (Fig. 3E). These results show that myricetin significantly inhibits PCa growth and the EMT in mouse models.

\section{Myricetin inhibits PCa lung and bone metastasis in mouse models}

To further investigate the anti-metastasis effects of myricetin on PCa cells in vivo, we inoculated PC3-luc-mCfp cells into the tail vein and tibial medullary cavity of nude mice to establish lung and bone metastasis mouse models, respectively. The photon fluxes of the lung metastasis model indicated that myricetin significantly reduced the metastatic burden in the lung (Fig. 4A). The numbers of mCherry-positive CTCs from whole-blood samples of the lung metastasis model mice were examined by flow cytometry at the end of the treatment (Fig.

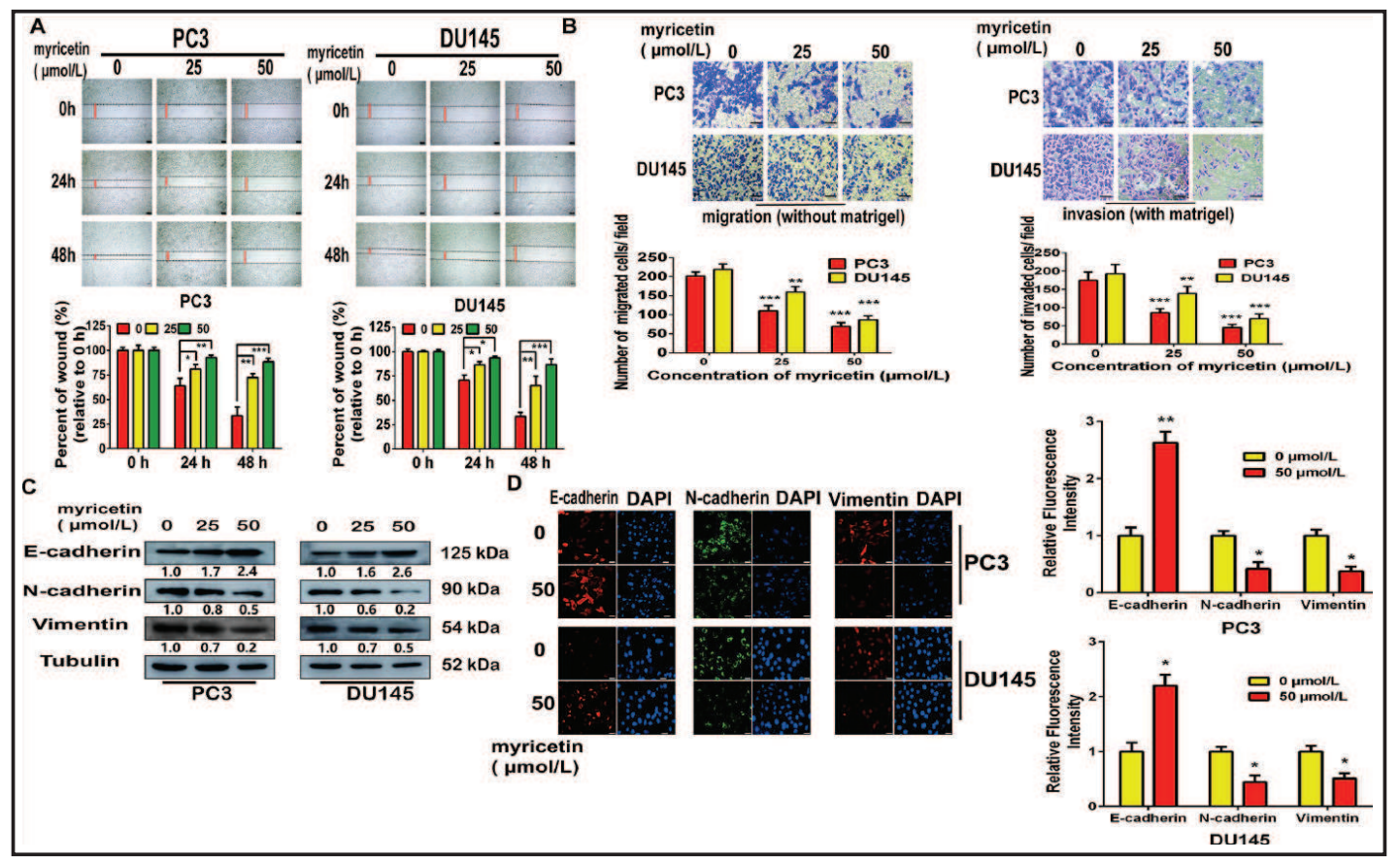

Fig. 2. Myricetin inhibits migration, invasion, and the EMT in PCa cells. (A) In a wound-healing assay, PC3 and DU145 cells were treated with 0,25 , or $50 \mu \mathrm{mol} / \mathrm{L}$ myricetin for $48 \mathrm{~h}$. The wound width was measured at the indicated times. Images are representative of at least three independent experiments. Quantification analysis is presented in the lower panel. Scale bar, $100 \mu \mathrm{m}$. (B) In Transwell assays (with or without a Matrigel-coated membrane), PC3 and DU145 cells were treated with 0, 25, or $50 \mu \mathrm{mol} / \mathrm{L}$ myricetin for $48 \mathrm{~h}$ in upper chambers. Migrated and invading cells were stained with crystal violet. Images are representative of five random fields of each membrane in a single experiment. Quantification analysis is presented in the lower panel. Scale bar, $100 \mu \mathrm{m}$. (C and D) EMT marker levels were analyzed by WB and IF in PC3 and DU145 cells. Cells were treated with 0,25 , or $50 \mu \mathrm{mol} / \mathrm{L}$ myricetin for $48 \mathrm{~h}$. IF images are representative of at least three independent experiments. Quantification analysis is presented in the right panel. Scale bar, $20 \mu \mathrm{m}$. 


\section{Cellular Physiology Cell Physiol Biochem 2018;48:1230-1244 \begin{tabular}{l|l} 
DOI: 10.1159/000492009 & $\begin{array}{l}\text { O } 2018 \text { The Author(s). Published by S. Karger AG, Basel } \\
\text { www.karger.com/cpb }\end{array}$
\end{tabular} and Biochemistry $\frac{\text { Pe et al: Myricetin Represses Prostate Cancer Progression by Inhibiting PIM1 and PIM1/ }}{\text { P. }}$ CXCR4 Interaction}

Fig. 3. Myricetin inhibits tumor growth and the EMT in PC3 xenograft mouse models. (A) Excised PC3 xenograft tumors of vehicle $(\mathrm{n}=6)$ and myricetin $(\mathrm{n}=6)$ groups. (B) PC3 xenograft tumor growth curves of vehicle and myricetin groups. (C) Analysis of cleaved caspase- 3 and Ki-67 expression in PC3 xenograft tumors of vehicle and myricetin groups by IHC. IHC images are representative of all xenograft tumors. Quantification analysis is presented in the right panel. Scale bar, $20 \mu \mathrm{m}$. (D) Analysis of EMT markers in PC3 xenograft tumors of vehicle and myricetin groups by IHC. IHC images are representative of all xenograft tumors. Quantification analysis is presented in the right panel. Scale bar, 20

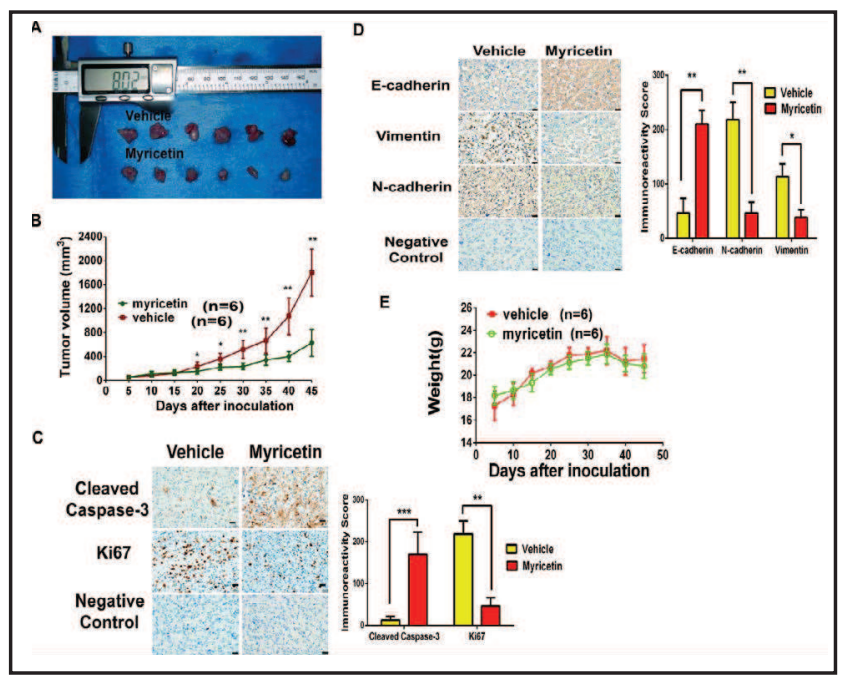
$\mu \mathrm{m}$. (E) Mouse body weight curves of vehicle and myricetin groups.

Fig. 4. Myricetin inhibits metastasis in PC3 tail vein and tibial medullary cavity injection mouse models. (A) Representative images (obtained with the IVIS Imaging System) of lung metastases in PC3 tail vein injection models of vehicle $(\mathrm{n}=6)$ and myricetin $(\mathrm{n}=6)$ groups $0,7,21$, and 42 days after cell inoculation. Luciferase signal intensity curves of lung metastases are presented in the left panel. (B) Representative flow cytometry analyses of whole-blood mCherry-labeled CTCs of all PC3 tail vein injection models. Blood samples were harvested from mice at the end of the experiment. Quantification

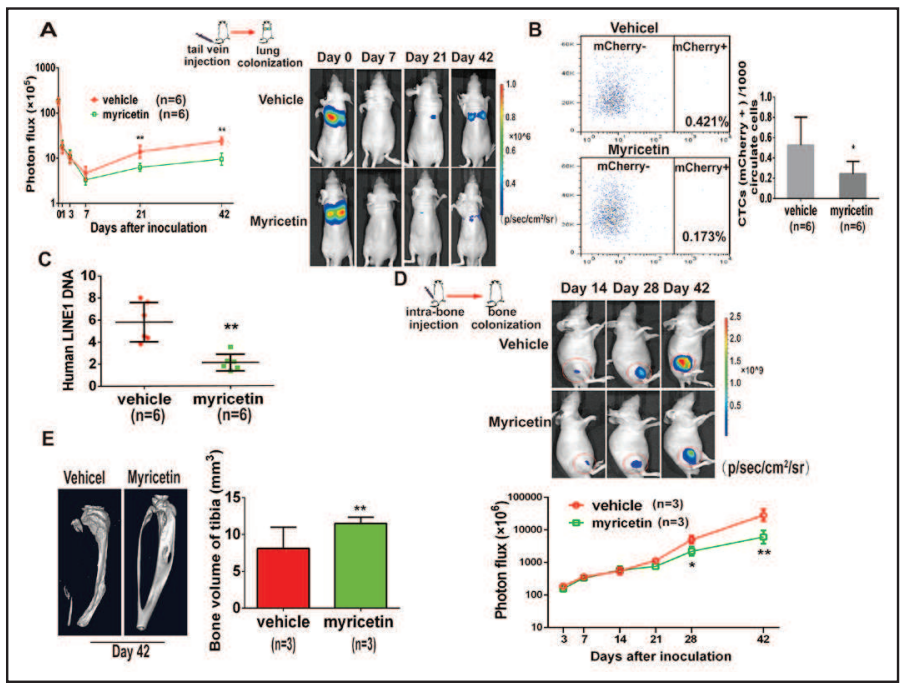
analysis is presented in the right panel.

(C) Analysis of whole-blood human LINE1 DNA levels by qRT-PCR. Expression levels were normalized to mouse LINE1 DNA. (D) Representative images (obtained with the IVIS Imaging System) of bone metastases in PC3 tibial medullary cavity injection models of vehicle $(n=3)$ and myricetin $(n=3)$ groups 14,28 , and 42 days after cell inoculation. Luciferase signal intensity curves of bone metastases are presented in the lower panel. (E) Representative images of tibial metastases by micro-CT scanning at the end of the experiment. Quantification analysis of micro-CT scanning-based tibial bone volume is presented in the right panel.

4B). The number of CTCs was much lower in the myricetin group than in the vehicle group. We also used qRT-PCR to investigate the levels of human long interspersed nuclear element 1 (LINE1), another indicator of CTCs [26], from the same whole-blood samples. The qRTPCR data were consistent with the above flow cytometry analysis (Fig. 4C). In addition, the photon fluxes of the bone metastasis model indicated that myricetin significantly reduced the metastatic burden in the tibia (Fig. 4D). Subsequently, micro-computed tomography (microCT) scanning and tibial bone volume analysis showed that myricetin significantly reduced osteolysis in the mouse models (Fig. 4E). These results show that myricetin significantly inhibits PCa metastasis in mouse models. 


\section{Cellular Physiology Cell Physiol Biochem 2018;48:1230-1244

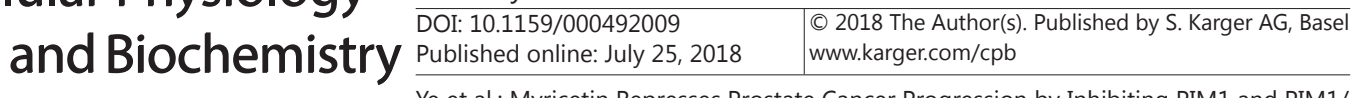 \\ Ye et al:: Myricetin Represses Prostate Cancer Progression by Inhibiting PIM1 and PIM1/ CXCR4 Interaction}

\section{Myricetin represses tumor progression by directly inhibiting PIM1 in PCa cells}

After observing the inhibitory effect of myricetin on tumor progression in $\mathrm{PCa}$, we investigated the potential mechanism underlying this effect. Myricetin can bind to the ATPbinding pocket of PIM1 and further inhibit its kinase activity [22]. Thus, we focused on the interaction between PIM1 and myricetin in PCa. Pull-down assays showed that epoxyactivated sepharose beads conjugated to myricetin could pull-down PIM1 (Fig. 5A, upper). However, under the same conditions, myricetin was hardly able to pull-down PIM2 (Fig. $5 \mathrm{~A}$, upper). A schematic further shows the crystal structure of PIM1 with myricetin (from the Protein Data Bank; ID: 2063) (Fig. 5A, lower), which displays the molecular interaction between PIM1 and myricetin. In addition, using WB, we determined PIM1 expression was highest in PC3 cells, second highest in DU145, third highest in C4-2, and fourth highest in RWPE-1 (Fig. 5B). Combined with the results of Fig. 1, we thus found that myricetin sensitivity was positively correlated with the PIM1 expression levels in different prostate cell lines. Then, we further used RNA interference to study the impact of PIM1 knockdown on the sensitivity of myricetin in PCa cells. qRT-PCR and WB analyses both showed that PIM1 levels were significantly decreased in PC3 and DU145 cells transfected with shPIM1 (Fig. 5C). Furthermore, in PCa cells, the $\mathrm{IC}_{50}$ of myricetin increased in the PIM1 knockdown counterparts (shPIM1) compared with their negative control-transfected (shNC) parental cell lines (from $45.9 \mu \mathrm{M}$ to $83.1 \mu \mathrm{M}$ for PC3; from $55.6 \mu \mathrm{M}$ to $89.01 \mu \mathrm{M}$ for DU145) (Fig. 5D). These results demonstrate that PCa cells lacking PIM1 expression are less sensitive to myricetin, suggesting that its anti-tumor effects are at least partly dependent on its ability to bind to PIM1.

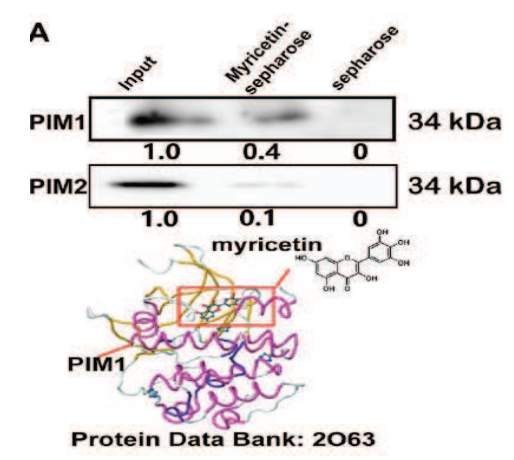

B

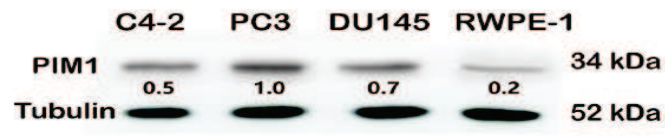

C

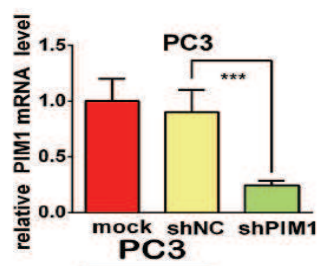

mock shNCshPIM1
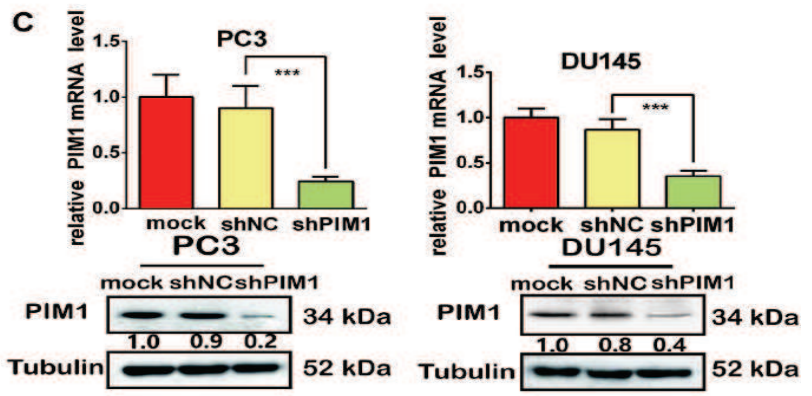

D
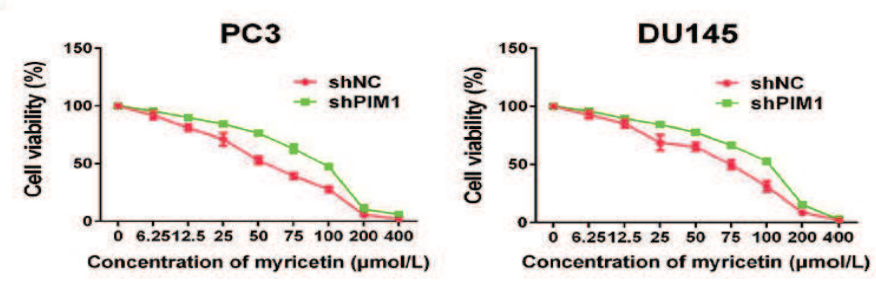

Fig. 5. Myricetin represses tumor progression by directly inhibiting PIM1 in PCa cells. (A) Myricetin-PIM1 and-PIM2 interactions analyzed by pull-down assay. Schematic of molecular interactions between myricetin and PIM1 are presented in the lower panel. (B) WB analysis of PIM1 protein expression in PC3, DU145, C4-2 and RWPE-1 cells. (C) qRT-PCR and WB analyses of PIM1 mRNA and protein expression in shNC- and shPIM1-transfected PC3 and DU145 cells. (D) CCK-8 assay of the effect of myricetin on the cell viability of shNC-and shPIM1-transfected PC3 and DU145 cells. Cells were treated with the indicated concentrations of myricetin for $48 \mathrm{~h}$. 


\section{Cellular Physiology \\ Cell Physiol Biochem 2018;48:1230-1244 \\ \begin{tabular}{ll|l} 
and Biochemistry & Dublished online: July 25, 2018 & $\begin{array}{l}\text { C } 2018 \text { The Author(s). Published by S. Karger AG, Basel } \\
\text { www.karger.com/cpb }\end{array}$ \\
\hline
\end{tabular}}

Ye et al.: Myricetin Represses Prostate Cancer Progression by Inhibiting PIM1 and PIM1/ CXCR4 Interaction

\section{Myricetin disrupts the interaction between PIM1 and CXCR4 in PCa cells}

CXCL12 is the specific chemokine ligand of CXCR4, and the CXCL12-CXCR4 axis plays important roles in the growth and metastasis of cancer $[27,28]$. The function of CXCR4 is mainly based on ligand-dependent or -independent internalization and surface reexpression, which depend on its intracellular C-terminal domain [29]. Other studies have found that PIM1 assists CXCR4 phosphorylation at Ser339 of the intracellular C-terminal domain and thereby facilitates CXCR4 cell surface expression and interaction with CXCL12 $[18,21]$. In a co-IP assay, we confirmed that PIM1 could bind to CXCR4 (Fig. 6A). Significantly, we further found that myricetin disrupted the PIM1/CXCR4 interaction (Fig. 6B). Accordingly, short-term nontoxic myricetin treatment $(0,25$, or $50 \mu \mathrm{M}$ for $2 \mathrm{~h})$ significantly decreased

A

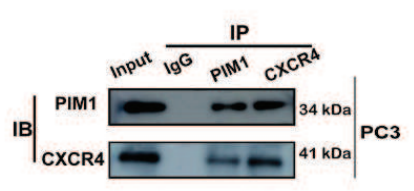

C

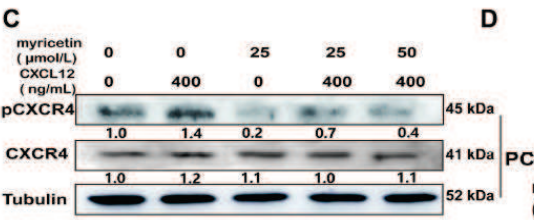

E
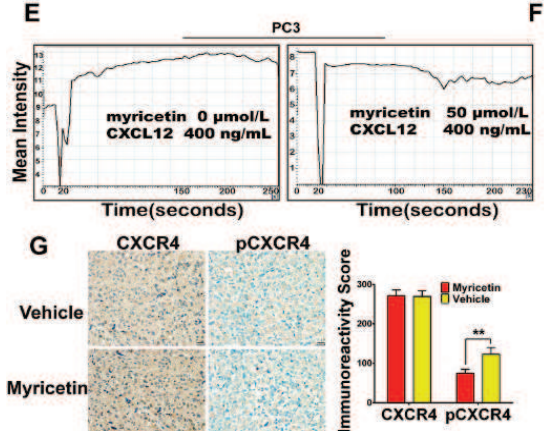

B
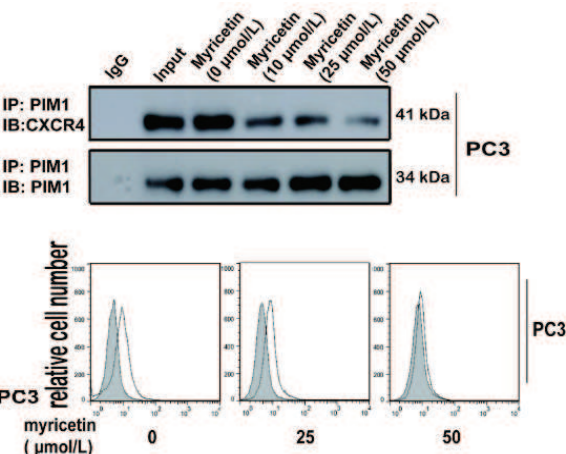

F $\operatorname{shN}$
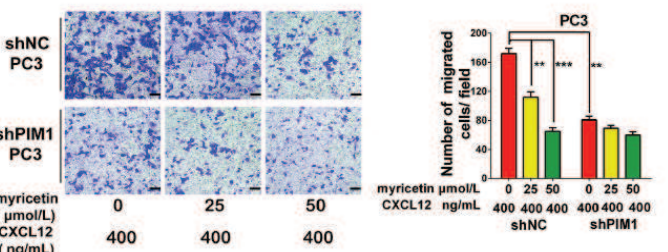

$\mathrm{CXCL12}$
$(\mathrm{ng} / \mathrm{mL})$$\quad 400 \quad 400$

400

Fig. 6. Myricetin-mediated PIM1 inhibition represses CXCR4 function in PCa cells. (A) The PIM1/CXCR4 interaction analyzed by co-IP assay. (B) Effect of myricetin on the PIM1/CXCR4 interaction was analyzed by co-IP assay. Cells were treated with $0,10,25$, or $50 \mu \mathrm{mol} / \mathrm{L}$ myricetin for $12 \mathrm{~h}$. (C) WB analysis of CXCL12induced CXCR4 phosphorylation. Cells were pretreated with 0,25 , or $50 \mu \mathrm{mol} / \mathrm{L}$ myricetin for $2 \mathrm{~h}$. Then, after being washed with PBS, cells were further treated with 0 or $400 \mathrm{ng} / \mathrm{mL}$ CXCL12 for $1 \mathrm{~h}$. (D) Cell surface expression of CXCR4 in PC3 cells examined by flow cytometry analysis. Cells were treated with 0,25 , or 50 $\mu \mathrm{mol} / \mathrm{L}$ myricetin for $2 \mathrm{~h}$. Then, after being washed with PBS, cells were stained with a PE-conjugated antihuman CD184 antibody (open histogram) and an isotype control mouse IgG2a (gray histogram). Images are representative of at least three independent experiments. (E) Analysis of the CXCL12-CXCR4 axis-mediated $\mathrm{Ca}^{2+}$ flux in PC3 cells by confocal microscope real-time monitoring. Cells were pretreated with 0 or 50 $\mu \mathrm{mol} / \mathrm{L}$ myricetin for $4 \mathrm{~h}$. After Fluo-4 incubation, cells were stimulated with $400 \mathrm{ng} / \mathrm{mL}$ CXCL12. Images are representative of at least three independent experiments. (F) Analysis of CXCL12-induced cell migration by Transwell assay (without Matrigel). ShNC- and shPIM1-treated PC3 cells were pretreated with 0, 25, or $50 \mu \mathrm{mol} / \mathrm{L}$ myricetin for $4 \mathrm{~h}$. Then, after being washed with PBS, cells were seeded and cultured in the upper chamber with serum-free medium and allowed to migrate toward a $400 \mathrm{ng} / \mathrm{mL}$ CXCL12 gradient for $24 \mathrm{~h}$. Migrated cells were stained with crystal violet. Images are representative of five random fields of each membrane in a single experiment. Quantification analysis is presented in the right panel. Scale bar, $100 \mu \mathrm{m}$. (G) Analysis of CXCR4 and pCXCR4 expression in PC3 xenograft tumors of vehicle and myricetin groups by IHC. IHC images are representative of all xenograft tumors. Quantification analysis is presented in the right panel. Scale bar, $20 \mu \mathrm{m}$. 


\section{Cellular Physiology Cell Physiol Biochem 2018;48:1230-1244

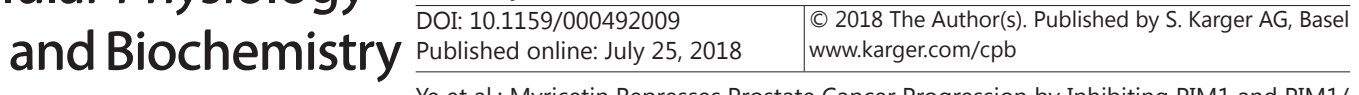 \\ Ye et al.: Myricetin Represses Prostate Cancer Progression by Inhibiting PIM1 and PIM1/ CXCR4 Interaction}

CXCL12-induced phosphorylation at Ser339 by WB (Fig. 6C). Consistently, flow cytometry analysis showed that myricetin also repressed CXCR4 surface expression in PC3 cells (Fig. 6D). Moreover, an intracellular $\mathrm{Ca}^{2+}$ flux assay also showed that myricetin pretreatment $(0$ or $50 \mu \mathrm{M}$ for $4 \mathrm{~h}$ ) significantly decreased the ability of CXCL12 to instantaneously induce $\mathrm{Ca}^{2+}$ flux in PC3 cells (Fig. 6E). These results show that myricetin disrupts the PIM1/CXCR4 interaction and inhibits the CXCL12-CXCR4 axis in PCa cells. Then, to further determine the essential role of PIM1 in myricetin-mediated CXCL12-CXCR4 inhibition, CXCL12induced chemotactic migration was tested by Transwell assay (without a Matrigel-coated membrane) in shNC- and shPIM1-transfected PC3 cells. As expected, myricetin significantly inhibited CXCL12-induced migration in shNC cells. However, although knockdown of PIM1 had inhibited CXCL12-induced migration, which is consistent with a previous study [21], myricetin did not further strengthen the inhibitory effect in shPIM1 cells (Fig. 6F). Moreover, IHC staining showed that the level of phosphorylated CXCR4 was significantly lower in PC3 subcutaneous xenograft tumor samples of the myricetin group than in those of the vehicle group (Fig. 6G). These results confirm that repression of CXCR4 function is primarily based on PIM1 inhibition and demonstrate that blockage of the PIM1/CXCR4 interaction is an important anti-cancer mechanism of myricetin in PCa.

Coexpression of PIM1 and CXCR4 is correlated with the poor prognosis of human $P C a$

Based on the interaction between PIM1 and CXCR4, we investigated whether PIM1 and CXCR4 expression are correlated in PCa. First, the correlation analysis of data mined from the ONCOMINE database showed that PIM1 mRNA expression was significantly positively correlated with CXCR4 in PCa tissues from the Wallace Prostate dataset $(r=0.4705 ; p$ $<0.0001 ; n=69$ ) and the Taylor Prostate dataset $(\mathrm{r}=0.5634$; $\mathrm{p}<0.0001 ; \mathrm{n}=131$ ) (Fig. 7A). Furthermore, we conducted IHC analysis in PCa specimens from 76 patients. Semiquantitative scoring of the IHC consistently revealed a positive correlation between PIM1 and CXCR4 protein expression $(\mathrm{r}=0.5108$; $\mathrm{p}<0.0001 ; \mathrm{n}=76$ ) (Fig. 7B and $\mathrm{C}$ ). We further investigated the correlation between PIM1 and CXCR4 expression and the clinicopathologic characteristics and prognosis of PCa patients. Using 76 tumor tissue specimens of PCa patients and based on PIM1 and CXCR4 expression levels, all patients were classified into four groups (both low; PIM1 high, CXCR4

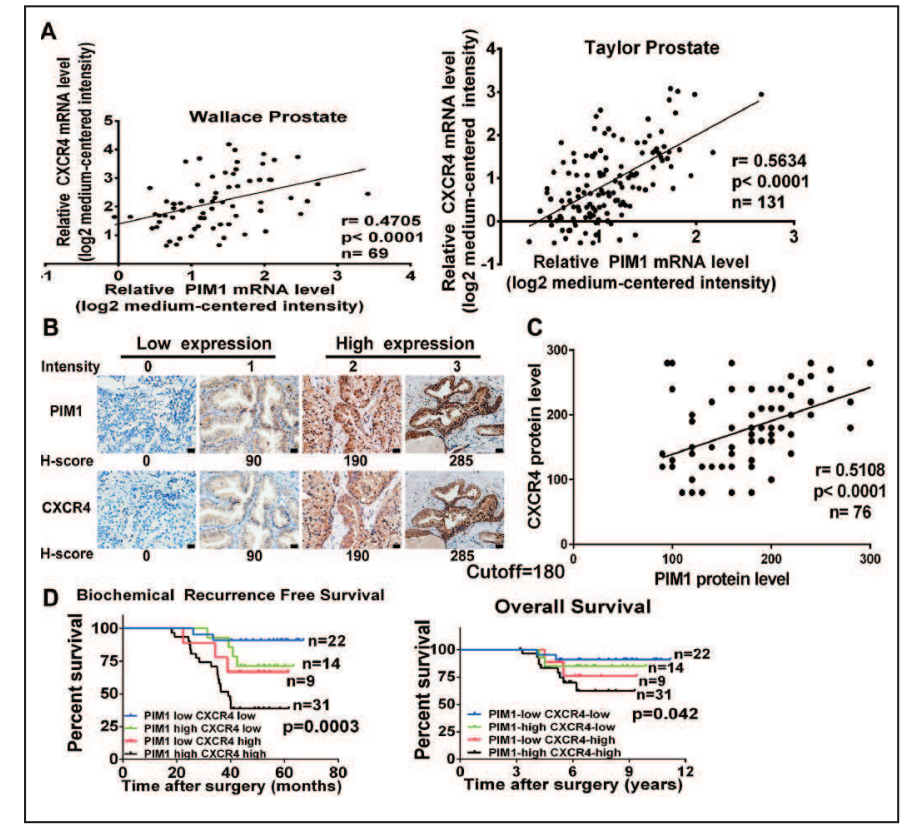

Fig. 7. PIM1 and CXCR4 are coexpressed and associated with poor prognosis in human PCa. (A) mRNA level correlation analysis between PIM1 and CXCR4 in PCa tissues from the prostate datasets of Wallace and Taylor. Spearman's correlation method was used for the analysis. (B) Representative IHC staining of PIM1 and CXCR4 in all PCa specimens is shown. Scale bar, $20 \mu \mathrm{m}$. (C) Protein level correlation between PIM1 and CXCR4 analyzed based on the IHC H-score of all PCa specimens. Spearman's correlation method was used for the analysis. (D) Kaplan-Meier curves for biochemical recurrence-free survival and overall survival of PCa patients. Survival analysis was performed according to the combined expression levels of PIM1 and CXCR4 in PCa specimens. 


\section{Cellular Physiology \\ Cell Physiol Biochem 2018;48:1230-1244

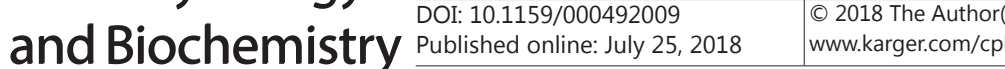 \\ Ye et al.: Myricetin Represses Prostate Cancer Progression by Inhibiting PIM1 and PIM1/ CXCR4 Interaction}

Table 1. Clinicopathologic characteristics of 76 PCa patients according to PIM1 and CXCR4 expression levels. * Statistical significance was calculated by chi-square test or fisher's exact test

\begin{tabular}{|c|c|c|c|c|c|}
\hline \multirow[t]{2}{*}{ Characteristics } & \multicolumn{4}{|c|}{ PIM1/CXCR4 expression } & \multirow[t]{2}{*}{ p value* } \\
\hline & Both low $(n=22)$ & $\begin{array}{c}\text { PIM1 high } \\
\text { CXCR4 low }(n=14)\end{array}$ & $\begin{array}{c}\text { PIM1 low } \\
\text { CXCR4 high }(n=9)\end{array}$ & Both high $(n=31)$ & \\
\hline Age & & & & & 0.546 \\
\hline$<70$ & 14 & 8 & 4 & 14 & \\
\hline$\geq 70$ & 8 & 6 & 5 & 17 & \\
\hline Preoperative PSA & & & & & \\
\hline$<10 \mathrm{ng} / \mathrm{mL}$ & 5 & 4 & 2 & 8 & 0.983 \\
\hline $10-20 \mathrm{ng} / \mathrm{mL}$ & 7 & 6 & 3 & 11 & \\
\hline$>20 \mathrm{ng} / \mathrm{mL}$ & 10 & 4 & 4 & 12 & \\
\hline Gleason score & & & & & 0.903 \\
\hline$<7$ & 10 & 6 & 3 & 15 & \\
\hline$\geq 7$ & 12 & 8 & 6 & 16 & \\
\hline Clinical stage & & & & & 0.001 \\
\hline $\mathrm{T} 1$ & 17 & 7 & 3 & 7 & \\
\hline T2/T3 & 5 & 7 & 6 & 24 & \\
\hline Seminal vesicle invasion & & & & & 0.012 \\
\hline Yes & 7 & 5 & 4 & 22 & \\
\hline No & 15 & 9 & 5 & 8 & \\
\hline Lymph node metastasis & & & & & 0.03 \\
\hline Yes & 6 & 6 & 5 & 21 & \\
\hline No & 16 & 8 & 4 & 10 & \\
\hline Biochemical recurrence & & & & & \\
\hline Yes & 6 & 7 & 3 & 24 & 0.02 \\
\hline No & 16 & 7 & 6 & 7 & \\
\hline
\end{tabular}

low; PIM1 low, CXCR4 high; both high). We found that double high expression of PIM1 and CXCR4 was significantly correlated with aggressive clinicopathologic traits (clinical stage, seminal vesicle invasion, lymph node metastasis, biochemical recurrence) and could predict a poor prognosis for PCa patients (Table 1 and Fig. 7D).

\section{Discussion}

Despite recent improvements in hormonotherapy and chemotherapy [30], there is still a scarcity of effective and personalized medicine for patients with advanced metastatic PCa. Small-molecule inhibitors have been recognized as promising anti-tumor therapeutic avenues [31, 32], but there are no effective target inhibitors for advanced PCa. Many types of natural compounds found in foods and herbs have been shown to possess anti-cancer effects. Thus, natural compounds are also a promising resource for the development of antitumor small-molecule inhibitors for PCa [3].

PIM1, a member of the PIM kinase family, plays important roles in cellular signal transduction pathways related to cell proliferation and survival [16]. PIM1 overexpression has been found in many cancers, including hematopoietic malignancies and $\mathrm{PCa}$, and is associated with tumorigenesis and malignant progression [33]. Moreover, PIM1 knockout is nonlethal without any obvious phenotypic changes [34]. Thus, PIM1 has become an attractive target for cancer therapy. Thus far, several PIM1 inhibitors, such as SGI-1776, have been tested in clinical trials. Unfortunately, the toxic side effects of SGI-1776 limit its clinical application [35]. Cell-free experiments have shown that the flavonoid compound myricetin binds to the ATP-binding pocket of PIM1 and inhibits its kinase activity [22]. Although some reports have demonstrated that flavonoid compounds exhibit anti-cancer effects in many cancers [2], there is still a lack of comprehensive studies of the anti-cancer effects and mechanism of the myricetin/PIM1 interaction in PCa.

Previous studies have shown that myricetin exhibits potent anti-cancer properties. Myricetin inhibits proliferation and promotes apoptosis in many types of cancer, such as liver, pancreatic, and colon cancer [10, 36, 37]. Moreover, myricetin also suppresses UVBinduced skin cancer and acts as an estrogen receptor agonist in breast cancer [7, 38]. We also found that myricetin showed selective cytotoxic and apoptosis-promoting effects in PCa cells (PC3, DU145, and C4-2) in vitro, which supports earlier findings [36, 39-41]. WB results further showed that apoptosis-associated proteins were upregulated, whereas the phosphorylation levels of ERK1/2 and AKT were downregulated. Furthermore, the in vivo results consistently showed that myricetin effectively suppressed the growth of subcutaneous 


\section{Cellular Physiology Cell Physiol Biochem 2018;48:1230-1244 \\ \begin{tabular}{ll|l} 
and Biochemistry $10.1159 / 000492009$ & $\begin{array}{l}\text { O } 2018 \text { The Author(s). Published by S. Karger AG, Base } \\
\text { www.karger.com/cpb }\end{array}$ \\
\cline { 2 - 3 } & Published online: July 25, 2018 &
\end{tabular} \\ Ye et al.: Myricetin Represses Prostate Cancer Progression by Inhibiting PIM1 and PIM1/ CXCR4 Interaction}

xenograft tumors. In addition, we found that myricetin significantly inhibited the migration, invasion, and metastasis of PCa in vitro and in vivo, which is consistent with research into glioblastoma and lung cancer $[12,13]$. Micro-CT scanning analysis further showed that PC3 cell-induced osteolysis of bone metastasis was significantly inhibited by myricetin in mouse models. Other work has revealed that myricetin induces osteoblast maturation and inhibits osteolysis [42,43], which might explain our outcomes from another aspect. Additionally, we also found that the EMT was inhibited by myricetin in vitro and in vivo. Collectively, the above results comprehensively demonstrate that myricetin effectively represses PCa malignant progression.

Because previous cell-free assays have revealed that myricetin inhibits PIM1 kinase activity [22], we considered PIM1 to be a potential specific and direct molecular target of myricetin in PCa cells. In our results, as expected, pull-down assays showed that epoxyactivated sepharose beads conjugated to myricetin could pull-down PIM1. Moreover, we observed that the $\mathrm{IC}_{50}$ of myricetin increased in PCa cells after PIM1 knockdown, which demonstrated that knockdown of PIM1 causes insensitivity to myricetin.

As a serine/threonine kinase, PIM1 usually cooperates and synergizes with some tumor-related genes, such as CXCR4 [18]. CXCR4 plays an important role in directing metastatic tumor cells to organs expressing CXCL12 and promotes the survival and growth of tumor cells in distant metastases [27, 44]. Because PIM1 can functionally regulate CXCR4 by boosting CXCR4 phosphorylation and surface expression in leukemia and PCa cells [18, 21], we further assessed whether myricetin could functionally repress the CXCL12-CXCR4 axis in PCa cells by inhibiting PIM1. First, we confirmed that PIM1 could bind to CXCR4 by co-IP assay. Then, as expected, we further observed that myricetin functionally disrupted the PIM1/CXCR4 interaction and further inhibited the CXCL12-CXCR4 axis in PCa cells. However, our data show that myricetin has a slight inhibitory effect on CXCL12-induced migration in shPIM1 cells, which suggests that the inhibitory effect of myricetin on the CXCL12CXCR4 axis is dependent on inhibiting PIM1 in PCa cells. These results demonstrate that blockage of the PIM1/CXCR4 functional interaction is an important anti-tumor mechanism of myricetin. Given the prospect of clinical individualized medication, we continued to study the clinical correlation of PIM1 and CXCR4 in PCa. Our data showed that PIM1 and CXCR4 are coexpressed in PCa and that the concomitant elevated expression of PIM1 and CXCR4 is significantly correlated with aggressive clinicopathologic traits and poor prognosis in $\mathrm{PCa}$ patients. Therefore, these results further demonstrate that myricetin might be more suitable for PCa patients with higher levels of PIM1 and CXCR4.

In conclusion, our study shows that myricetin can play an important role in repressing PCa progression by inhibiting PIM1 and disrupting the PIM1/CXCR4 interaction. These actions make it a novel potential anti-growth and anti-metastasis agent for the comprehensive treatment of PCa. Meanwhile, we also need to further pharmacologically modify myricetin to improve its clinical availability and selectivity in future studies.

\section{Acknowledgements}

This work was supported by the National Natural Science and Technology Major Project of China (No. 20122X09303011-002), the Shanghai Pujiang Program (No. 16PJ1411100), the Research fund of Shanghai municipal health and family planning commission (No. 2017Y0019), and the Natural Science Foundation of Shanghai (No.18ZR1438400).

\section{Disclosure Statement}

The authors declare no potential conflicts of interests.

\section{References}

1 Torre LA, Bray F, Siegel RL, Ferlay J, Lortet-Tieulent J, Jemal A: Global cancer statistics, 2012. CA Cancer J Clin 2015;65:87-108. 


\section{Cellular Physiology Cell Physiol Biochem 2018;48:1230-1244 \begin{tabular}{ll|l} 
DOI: 10.1159/000492009 & $\begin{array}{l}\text { () 2018 The Author(s). Published by S. Karger AG, Basel } \\
\text { www.karger.com/cpb }\end{array}$ \\
\cline { 2 - 3 }
\end{tabular}}

Ye et al.: Myricetin Represses Prostate Cancer Progression by Inhibiting PIM1 and PIM1/ CXCR4 Interaction

2 Chahar MK, Sharma N, Dobhal MP, Joshi YC: Flavonoids: A versatile source of anticancer drugs. Pharmacogn Rev 2011;5:1-12.

-3 Weng CJ, Yen GC: Flavonoids, a ubiquitous dietary phenolic subclass, exert extensive in vitro anti-invasive and in vivo anti-metastatic activities. Cancer Metastasis Rev 2012;31:323-351.

-4 Yuan CH, Filippova M, Krstenansky JL, Duerksen-Hughes PJ: Flavonol and imidazole derivatives block HPV16 E6 activities and reactivate apoptotic pathways in HPV ${ }^{+}$cells. Cell Death Dis 2016;7:2060.

-5 Bie B, Sun J, Li J, Guo Y, Jiang W, Huang C, Yang J, Li Z: Baicalein, a Natural Anti-Cancer Compound, Alters MicroRNA Expression Profiles in Bel-7402 Human Hepatocellular Carcinoma Cells. Cell Physiol Biochem 2017;41:1519-1531.

6 Sun DW, Zhang HD, Mao L, Mao CF, Chen W, Cui M, Ma R, Cao HX, Jing CW, Wang Z, Wu JZ, Tang JH: Luteolin Inhibits Breast Cancer Development and Progression In vitro and In vivo by Suppressing Notch Signaling and Regulating MiRNAs. Cell Physiol Biochem 2015;37:1693-1711.

-7 Maggiolini M, Recchia AG, Bonofiglio D, Catalano S, Vivacqua A, Carpino A, Rago V, Rossi R, Andò S: The red wine phenolics piceatannol and myricetin act as agonists for estrogen receptor alpha in human breast cancer cells. J Mol Endocrinol 2005;35:269-281.

8 Nöthlings U, Murphy SP, Wilkens LR, Henderson BE, Kolonel LN: Flavonols and pancreatic cancer risk: the multiethnic cohort study. Am J Epidemiol 2007;166:924-931.

-9 Geybels MS, Verhage BA, Arts IC, van Schooten FJ, Goldbohm RA, van den Brandt PA: Dietary flavonoid intake, black tea consumption, and risk of overall and advanced stage prostate cancer. Am J Epidemiol 2013;177:1388-1398.

10 Iyer SC, Gopal A, Halagowder D: Myricetin induces apoptosis by inhibiting P21 activated kinase 1 (PAK1) signaling cascade in hepatocellular carcinoma. Mol Cell Biochem 2015;407:223-237.

-11 Xu R, Zhang Y, Ye X, Xue S, Shi J, Pan J, Chen Q: Inhibition effects and induction of apoptosis of flavonoids on the prostate cancer cell line PC-3 in vitro. Food Chem 2013;138:48-53.

$>12$ Shih YW, Wu PF, Lee YC, Shi MD, Chiang TA: Myricetin suppresses invasion and migration of human lung adenocarcinoma A549 cells: possible mediation by blocking the ERK signaling pathway. J Agric Food Chem 2009;57:3490-3499.

13 Chiu WT, Shen SC, Chow JM, Lin CW, Shia LT, Chen YC: Contribution of reactive oxygen species to migration/ invasion of human glioblastoma cells U87 via ERK-dependent COX-2/PGE(2) activation. Neurobiol Dis 2010;37:118-129.

14 Jung SK, Lee KW, Byun S, Lee EJ, Kim JE, Bode AM, Dong Z, Lee HJ: Myricetin inhibits UVB-induced angiogenesis by regulating PI-3 kinase in vivo. Carcinogenesis 2010;31:911-917.

-15 Siegelin MD, Gaiser T, Habel A, Siegelin Y: Myricetin sensitizes malignant glioma cells to TRAIL-mediated apoptosis by down-regulation of the short isoform of FLIP and bcl-2. Cancer Lett 2009;283:230-238.

16 Nawijn MC, Alendar A, Berns A: For better or for worse: the role of Pim oncogenes in tumorigenesis. Nat Rev Cancer 2011;11:23-34.

-17 Dhanasekaran SM, Barrette TR, Ghosh D, Shah R, Varambally S, Kurachi K, Pienta KJ, Rubin MA, Chinnaiyan AM: Delineation of prognostic biomarkers in prostate cancer. Nature 2001;412:822-826.

-18 Santio NM, Eerola SK, Paatero I, Yli-Kauhaluoma J, Anizon F, Moreau P, Tuomela J, Härkönen P, Koskinen PJ: Pim Kinases Promote Migration and Metastatic Growth of Prostate Cancer Xenografts. PLoS One 2015;10:e0130340.

-19 Linn DE, Yang X, Xie Y, Alfano A, Deshmukh D, Wang X, Shimelis H, Chen H, Li W, Xu K, Chen M, Qiu Y: Differential regulation of androgen receptor by PIM-1 kinases via phosphorylation-dependent recruitment of distinct ubiquitin E3 ligases. J Biol Chem 2012;287:22959-22968.

-20 Santio NM, Salmela M, Arola H, Eerola SK, Heino J, Rainio EM, Koskinen PJ: The PIM1 kinase promotes prostate cancer cell migration and adhesion via multiple signalling pathways. Exp Cell Res 2016;342:113124.

-21 Grundler R, Brault L, Gasser C, Bullock AN, Dechow T, Woetzel S, Pogacic V, Villa A, Ehret S, Berridge G, Spoo A, Dierks C, Biondi A, Knapp S, Duyster J, Schwaller J: Dissection of PIM serine/threonine kinases in FLT3ITD-induced leukemogenesis reveals PIM1 as regulator of CXCL12-CXCR4-mediated homing and migration. J Exp Med 2009;206:1957-1970.

- 22 Holder S, Zemskova M, Zhang C, Tabrizizad M, Bremer R, Neidigh JW, Lilly MB: Characterization of a potent and selective small-molecule inhibitor of the PIM1 kinase. Mol Cancer Ther 2007;6:163-172.

-23 Thalmann GN, Anezinis PE, Chang SM, Zhau HE, Kim EE, Hopwood VL, Pathak S, von EAC, Chung LW: Androgen-independent cancer progression and bone metastasis in the LNCaP model of human prostate cancer. Cancer Res 1994;54:2577-2581. 


\section{Cellular Physiology Cell Physiol Biochem 2018;48:1230-1244 \begin{tabular}{ll|l} 
and Biochemistry & $\begin{array}{l}\text { DOI: 10.1159/000492009 } \\
\text { Published online: July 25, } 2018\end{array}$ & $\begin{array}{l}\text { C } 2018 \text { The Author(s). Published by S. Karger AG, Basel } \\
\text { www.karger.com/cpb }\end{array}$ \\
\cline { 2 - 3 }
\end{tabular} \\ Ye et al.: Myricetin Represses Prostate Cancer Progression by Inhibiting PIM1 and PIM1/ CXCR4 Interaction}

-24 Christoph DC, Asuncion BR, Mascaux C, Tran C, Lu X, Wynes MW, Gauler TC, Wohlschlaeger J, Theegarten D, Neumann V, Hepp R, Welter S, Stamatis G, Tannapfel A, Schuler M, Eberhardt WE, Hirsch FR: Folylpolyglutamate synthetase expression is associated with tumor response and outcome from pemetrexed-based chemotherapy in malignant pleural mesothelioma. J Thorac Oncol 2012;7:1440-1448.

25 Bill R, Christofori G: The relevance of EMT in breast cancer metastasis: Correlation or causality. FEBS Lett 2015;589:1577-1587.

26 Yuan JH, Yang F, Wang F, Ma JZ, Guo YJ, Tao QF, Liu F, Pan W, Wang TT, Zhou CC, Wang SB, Wang YZ, Yang Y, Yang N, Zhou WP, Yang GS, Sun SH: A long noncoding RNA activated by TGF- $\beta$ promotes the invasionmetastasis cascade in hepatocellular carcinoma. Cancer Cell 2014;25:666-681.

27 Teicher BA, Fricker SP: CXCL12 (SDF-1)/CXCR4 pathway in cancer. Clin Cancer Res 2010;16:2927-2931.

-28 Conley-LaComb MK, Saliganan A, Kandagatla P, Chen YQ Cher ML, Chinni SR: PTEN loss mediated Akt activation promotes prostate tumor growth and metastasis via CXCL12/CXCR4 signaling. Mol Cancer 2013;12:85.

29 Busillo JM, Benovic JL: Regulation of CXCR4 signaling. Biochim Biophys Acta 2007;1768:952-963.

-30 Sweeney CJ, Chen YH, Carducci M, Liu G, Jarrard DF, Eisenberger M, Wong YN, Hahn N, Kohli M, Cooney MM, Dreicer R, Vogelzang NJ, Picus J, Shevrin D, Hussain M, Garcia JA, DiPaola RS: Chemohormonal Therapy in Metastatic Hormone-Sensitive Prostate Cancer. N Engl J Med 2015;373:737-746.

-31 Buchler T, Bortlicek Z, Poprach A, Pavlik T, Veskrnova V, Honzirkova M, Zemanova M, Fiala O, Kubackova K, Slaby O, Svoboda M, Vyzula R, Dusek L, Melichar B: Outcomes for Patients with Metastatic Renal Cell Carcinoma Achieving a Complete Response on Targeted Therapy: A Registry-based Analysis. Eur Urol 2016;70:469-475.

-32 Ledermann J, Harter P, Gourley C, Friedlander M, Vergote I, Rustin G, Scott C, Meier W, Shapira-Frommer R, Safra T, Matei D, Macpherson E, Watkins C, Carmichael J, Matulonis U: Olaparib maintenance therapy in platinum-sensitive relapsed ovarian cancer. N Engl J Med 2012;366:1382-1392.

-33 Brault L, Gasser C, Bracher F, Huber K, Knapp S, Schwaller J: PIM serine/threonine kinases in the pathogenesis and therapy of hematologic malignancies and solid cancers. Haematologica 2010;95:10041015.

-34 Laird PW, van der Lugt NM, Clarke A, Domen J, Linders K, McWhir J, Berns A, Hooper M: In vivo analysis of Pim-1 deficiency. Nucleic Acids Res 1993;21:4750-4755.

-35 Le BT, Kumarasiri M, Adams JR, Yu M, Milne R, Sykes MJ, Wang S: Targeting Pim kinases for cancer treatment: opportunities and challenges. Future Med Chem 2015;7:35-53.

-36 Phillips PA, Sangwan V, Borja-Cacho D, Dudeja V, Vickers SM, Saluja AK: Myricetin induces pancreatic cancer cell death via the induction of apoptosis and inhibition of the phosphatidylinositol 3-kinase (PI3K) signaling pathway. Cancer Lett 2011;308:181-188.

-37 Kim ME, Ha TK, Yoon JH, Lee JS: Myricetin induces cell death of human colon cancer cells via BAX/BCL2dependent pathway. Anticancer Res 2014;34:701-706.

-38 Jung SK, Lee KW, Byun S, Kang NJ, Lim SH, Heo YS, Bode AM, Bowden GT, Lee HJ, Dong Z: Myricetin suppresses UVB-induced skin cancer by targeting Fyn. Cancer Res 2008;68:6021-6029.

-39 Huang H, Chen AY, Rojanasakul Y, Ye X, Rankin GO, Chen YC: Dietary compounds galangin and myricetin suppress ovarian cancer cell angiogenesis. J Funct Foods 2015;15:464-475.

-40 Feng J, Chen X, Wang Y, Du Y, Sun Q, Zang W, Zhao G: Myricetin inhibits proliferation and induces apoptosis and cell cycle arrest in gastric cancer cells. Mol Cell Biochem 2015;408:163-170.

41 Huang H, Chen AY, Ye X, Li B, Rojanasakul Y, Rankin GO, Chen YC: Myricetin inhibits proliferation of cisplatin-resistant cancer cells through a p53-dependent apoptotic pathway. Int J Oncol 2015;47:14941502.

-42 Hsu YL, Chang JK, Tsai CH, Chien TT, Kuo PL: Myricetin induces human osteoblast differentiation through bone morphogenetic protein-2/p38 mitogen-activated protein kinase pathway. Biochem Pharmacol 2007;73:504-514.

-43 Wu C, Wang W, Tian B, Liu X, Qu X, Zhai Z, Li H, Liu F, Fan Q, Tang T, Qin A, Zhu Z: Myricetin prevents titanium particle-induced osteolysis in vivo and inhibits RANKL-induced osteoclastogenesis in vitro. Biochem Pharmacol 2015;93:59-71.

44 Meads MB, Hazlehurst LA, Dalton WS: The bone marrow microenvironment as a tumor sanctuary and contributor to drug resistance. Clin Cancer Res 2008;14:2519-2526. 